\title{
Working Together in the Best Interest of Patients
}

\author{
Jean E. Johnson, $P h D, R N$
}

The findings by Peterson et al. show that over half of all family physicians work with nurse practitioners, physician assistants, and certified nurse midwives. While tensions surrounding leadership of teams remain an issue, there are many systems problems that all primary care providers need to face together. This commentary presents the challenges we need to address in order to keep the focus of our care on the patient. (J Am Board Fam Med 2013;26:241-243.)

There has been noteworthy attention given to interprofessional health care teams as an efficient and effective way of organizing and providing care for chronically ill individuals and populations. The Institute of Medicine identified teamwork and collaboration as critical competencies to provide safe, high-quality care. ${ }^{1}$ The Macy Interprofessional Collaborative Project released a report on education competencies necessary for the curricula of all health professionals. ${ }^{2}$ A second report defining team competencies, cosponsored by the Robert Wood Johnson Foundation, ABIM Foundation, Health Resources Service Administration, and Macy Foundation, was released. ${ }^{3}$ In addition, the Health Resources Administration has established the requirement for interprofessional activity in grant proposals for most of their grant programs, as noted in their recently released call for proposals. The Advisory Council on Primary Care and Dentistry, which advises the secretary of the Department of Health and Human Services, has chosen the topic of interprofessional education for their 10th report that will be released soon. The reason for the focus on interprofessional teams in primary

From School of Nursing, The George Washington University, Washington, DC.

Funding: none.

Conflict of interest: none declared.

Corresponding author: Jean E. Johnson, PhD, RN, School of Nursing, The George Washington University, $2030 \mathrm{M}$ street, NW Suite 300, Washington, DC 20037 (E-mail: jejohns@gwu.edu).

\section{See Related Article on Page 244.}

care is to expand the overall primary care workforce in conjunction with improving care.

Consistent with national efforts to increase interprofessional teams, the recent finding by Peterson et $\mathrm{al}^{4}{ }^{4}$ that more than $50 \%$ of family physicians (FPs) include nurse practitioners (NPs), certified nurse midwives (CNMs), and/or physician assistants (PAs) in their practices shows that these disciplines work well together in terms of the skill set needed for a primary care practice and that this likely is the practice model of the future. The dramatic increase in the number of interprofessional practices over the past 10 years suggests that the combination of FPs, NPs, CNMs, and PAs is at the very least a viable team in terms of both financial viability as well as patient care.

Interprofessional practice has long existed, with many models of high-performing teams. High-performing teams share several characteristics, including recognition of member contributions, effective communication, shared decision making, and shared vision and values. Attaining these characteristics suggest that there is trust and flexibility among the team members with regard to who will take responsibility for what aspect of the practice.

The purpose of working to achieve a high-functioning team is to provide high-quality care to patients. Providing high-quality care is going to be ever more important as the expectations around quality become linked to payment. Practices in which the clinicians are stable and satisfied with their work circumstances will likely be the practices that do well in our country's continually evolving health system.

Clearly, teamwork has been identified as an important component of improving patient care and 
includes FPs, NPs, and PAs working together. The research on NP, CMN, and PA practice has demonstrated consistently safe and quality care comparable to that provided by FPs. ${ }^{5-16}$ This has been reinforced again and again for NPs, CNMs, and PAs throughout decades of practice. However, the real issue is being able to work together for the good of patients and the health of the nation.

Although we know that there are benefits to working together, there continues to be tension, particularly between nursing and medicine, around independent practice and who should be the leader of a patient-centered medical home. Rather than NPs and FPs continuing to focus on issues of who is the captain of the team or who can have an independent practice, the overriding principle for continued dialogue should keep the patient at the center of our efforts. There is too much work to be done to meet the health care needs of the United States for nursing and medicine to be odds.

It will be much better for our patients if we agree to set aside the discussion about independent practice, supervision, and leading teams. It would be more productive to agree to disagree about these issues and focus on crucial challenges facing all primary care providers. These issues include:

- Organizing our scarce primary care workforce to meet the needs of all patients. With the addition of 40 million people to the primary care system, everyone's expertise and contribution is needed.

- Continuing to develop/participate in regional systems of care that can provide coordinated care, support regionally based electronic bealth records, and provide support for quality improvement programs. Days of "hanging out a shingle" are limited, with pressures for small practices to be part of regional systems.

- Engaging patients to be true partners in their bealth care. It is clear that patients are becoming more empowered, and people increasingly want to control their health care decisions. It is vital that patients engage more extensively in taking care of themselves to stay as healthy as possible and to manage acute and chronic illness in concert with their clinicians.

- Working together to influence the adoption of policies that support high-quality, reasonably funded primary care. If the different disciplines combined forces to achieve common interests, a lot more could be accomplished to support primary care.
The fact is that physicians will continue to be providers and leaders of many health care teams and NPs will continue to work to ensure practice to the full extent of their education. Neither discipline will convince the other to change its position, nor is it necessary to try. Keep in mind that $50 \%$ of family physicians have NPs, PAs, or both working with them. At the clinic level, things generally are worked out to the extent clinicians feel comfortable in a practice together. Practices will need to be attentive to developing collaborative, collegial practices to create the efficient and safe high-quality primary care system we need. We should move forward together on the important issues noted above-so much needs to be done.

\section{References}

1. Greiner A, Knebel E, Board on Health Care Services, Institute of Medicine, Committee on the Health Professions Education Summit. Health professions education : a bridge to quality. Washington, DC: National Academies Press; 2003.

2. Interprofessional Education Collaborative Expert Panel. Core competencies for interprofessional collaborative practice: report of an expert panel. Washington, DC: Interprofessional Education Collaborative; 2011.

3. Josiah Macy Jr. Foundation, ABIM Foundation, Robert Wood Johnson Foundation. Team-based competencies: building a shared foundation for education and clinical practice. Conference proceedings, February 16-17, 2011, Washington, DC. Available from http://macyfoundation.org/docs/macy_pubs/ Team-Based_Competencies.pdf. Accessed March 11, 2013.

4. Peterson LE, Phillips RL, Puffer JC, Bazemore A, Petterson S. Most family physicians work routinely with nurse practitioners, physician assistants, or certified nurse midwives. J Am Board Fam Med 2013; 26:244-245.

5. Brown SA, Grimes DE. A meta-analysis of nurse practitioners and nurse midwives in primary care. Nurs Res 1995;44:332-9.

6. Green LV, Savin S, Lu Y. Primary care physician shortages could be eliminated through use of teams, nonphysicians, and electronic communication. Health Aff (Millwood) 2013;32:11-9.

7. Henry LR, Hooker RS, Yates KL. The role of physician assistants in rural health care: a systematic review of the literature. J Rural Health 2011;27:220-9.

8. Hooker RS, Everett CM. The contributions of physician assistants in primary care systems. Health Soc Care Community 2012;20:20-31.

9. Landis NT. Patient outcomes comparable for primary care physicians, independent nurse practitioners. Am J Health Syst Pharm 2000;57:424, 426. 
10. Laurant M, Reeves D, Hermens R, Braspenning J, Grol R, Sibbald B. Substitution of doctors by nurses in primary care. Cochrane Database Syst Rev 2005; (2):CD001271.

11. Morgan PA, Abbott DH, McNeil RB, Fisher DA. Characteristics of primary care office visits to nurse practitioners, physician assistants and physicians in United States Veterans Health Administration facilities, 2005 to 2010: a retrospective cross-sectional analysis. Hum Resour Health 2012;10:42.

12. Mundinger MO, Kane RL. Health outcomes among patients treated by nurse practitioners or physicians. JAMA 2000;283:2521-4.

13. Newhouse RP, Stanik-Hutt J, White KM, et al. Advanced practice nurse outcomes 1990-2008: a systematic review. Nurs Econ 2011;29:230-50; quiz 251.
14. Schiff $M$. The role of nurse practitioners in meeting increasing demand for primary care. December 2012. Washington, DC: National Governors Association. Available from http://www.nga.org/cms/home/ nga-center-for-best-practices/center-publications/pagehealth-publications/col2-content/main-content-list/therole-of-nurse-practitioners.html. Accessed January 23, 2013.

15. U.S. Congress, Office of Technology Assessment. Nurse practitioners, physician assistants, and certified nurse-midwives: a policy analysis. OTA-HCS-37. Washington, DC: U.S. Government Printing Office; 1986. Available from http://www.fas.org/ota/reports/ 8615.pdf. Accessed January 23, 2013.

16. van der Linden C, Reijnen R, de Vos R. Diagnostic accuracy of emergency nurse practitioners versus physicians related to minor illnesses and injuries. J Emerg Nurs 2010;36:311-6. 